\title{
IL28B Genetic Variations in Patients with Recurrent Herpes Simplex Keratitis
}

\author{
Savić Borivoje ${ }^{1}$, Stanojlović Svetlana ${ }^{1,2}$, Hadži-Milić Milan ${ }^{3}$, Đonović Nela ${ }^{4}$, \\ Milošević-Đorđević Olivera ${ }^{5,6}$, Milisavljević Filip ${ }^{7}$, Stojković Milenko ${ }^{1,2}$ \\ and Pajić Srbislav ${ }^{8, *(D)}$ \\ 1 Clinic for Eye Diseases, Clinical Center of Serbia, 11000 Belgrade, Serbia; sb.bora@gmail.com (S.B.); \\ stanojlovic.svetlana@gmail.com (S.S.); milenko.stojkovic@mfub.bg.ac.rs (S.M.) \\ 2 Faculty of Medicine, University of Belgrade, 11000 Belgrade, Serbia \\ 3 Department of Surgery, Orthopedics and Ophthalmology, Faculty of Veterinary Medicine, 11000 Belgrade, \\ Serbia; milanhmilic@gmail.com \\ 4 Department of Hygiene and Ecology, Faculty of Medical Sciences, University of Kragujevac, \\ 34000 Kragujevac, Serbia; nela@medf.kg.ac.rs \\ 5 Department of Genetics, Faculty of Medical Science, University of Kragujevac, 34000 Kragujevac, Serbia; \\ olivera@kg.ac.rs \\ 6 Department of Biology and Ecology, Faculty of Science, University of Kragujevac, 34000 Kragujevac, Serbia \\ 7 Clinic of Neurosurgery, Clinical Center of Serbia, 11000 Belgrade, Serbia; milisavljevic93@gmail.com \\ 8 Emergency Center, Clinic for Emergency surgery, Clinical Center of Serbia, 11000 Belgrade, Serbia \\ * Correspondence: nevus-ng@hotmail.com; Tel.: +381-64-903-0226
}

Received: 9 September 2019; Accepted: 25 September 2019; Published: 26 September 2019

\begin{abstract}
Background and objectives: Recurrent herpes simplex keratitis (HSK) is the most common cause of corneal blindness in the developed world. A relationship between host gene polymorphisms and the recurrence of herpes simplex virus (HSV) infection has previously been proposed. Thus, the aim of this study was to investigate a potential association between the IL28B host genotype and recurrent HSK. Materials and Methods: Eighty patients older than 18 years of age of both genders with a history of recurrent herpes simplex labialis (HSL) were considered for inclusion. Seventy-five of these patients were found to be seropositive for HSV-1 and were subsequently enrolled in the study. Twenty-four of the enrolled patients also had a history of recurrent HSK associated with severe corneal scarring and visual acuity deterioration. Total DNA was isolated from whole blood samples. A single-nucleotide polymorphism (SNP) rs12979860 near the IL28B gene on chromosome 19 was genotyped. Results: A significant association was observed between recurrent HSK and two SNPs of the IL28B genotype (CCrs12979860 and CTrs12979860, $p<0.01$ ). The variation CCrs12979860 showed a significantly greater association with HSK (16 out of 26 patients) compared with CTrs12979860 (8 out of 34 patients). Conclusion: Seropositive individuals with a history of recurrent HSK are likely to have the CC IL28B genotype. This genotype may be related to incomplete control of the infection and more frequent periodical viral shedding along the first nerve branch of the trigeminal ganglion, which clinically manifests as recurrent herpes keratitis. The clinical manifestation of recurrent HSV-1 infection seems to be influenced by polymorphism of the IL28B genotype.
\end{abstract}

Keywords: type III interferons (IL28B) genotype; keratitis; herpes simplex virus type 1 (HSV-1)

\section{Introduction}

Herpes simplex virus (HSV) infection is ubiquitous in humans, infecting $50-90 \%$ of the world's population [1,2]. HSV-1 causes a wide range of diseases, including herpes labialis, gingivostomatitis, and keratitis. The prevalence of ocular HSV disease has been estimated to be 149 in a population of 
100,000 and in about one-fifth of the cases, leads to the development of stromal herpetic keratitis [3]. Herpes simplex keratitis (HSK) is one of the leading causes of corneal blindness, primarily because of its recurrent nature [4].

After primary infection of the sensory nerves innervating the skin and mucosal epithelium, HSV-1 has the ability to establish lifelong latency, most commonly within the trigeminal ganglion. The HSV-1 virus uses actin and microtubules for retrograde transport from the plasma membrane during entry and exit along axons. The composition of the viral particles, especially their protein complement, seems to determine the direction of transport during the entry and exit of the virus in neuronal and non-neuronal cells [5]. It has been estimated that one-third of the world's population suffers from recurrent HSV infections [3]. Upon periodical reactivation, the virus may follow any of the three branches of the fifth cranial nerve, regardless of the innervation branch of the primary HSV infection area. It is believed that cycles of HSV reactivation in latently infected neurons accompanied by anterograde axonal spread to the cornea lead to recurrent infections and scarring of the cornea [6]. Antiviral cytokine secretion as a result of host immunity plays a vital role in virus clearance; however, the concurrent inflammatory response is a major cause of corneal scarring, leading to vision loss [2,3,7].

The production of Type I interferons (IFNs) is most important for controlling viral replication [8]. Accordingly, enhanced HSV virulence has been reported in Type I IFN-receptor-deficient mice [9]. Interleukin (IL) 28B (interferon (IFN)- $\lambda 3$ ), together with IL-28A and IL-29 (also termed IFN- $\lambda 1$ and IFN- $\lambda 2$ ) constitute a new subfamily within the IL-10 interferon family [10]. Indeed, IFN- $\lambda$ exhibits a number of biological characteristics that are similar to those of IFN- $\alpha / \beta$, including antiviral activity, antiproliferative activity, and in vivo antitumor activity. By signaling through the heterodimeric IL-28R $\alpha /$ IL-10R $\beta$ complex, IFN- $\lambda$ performs antiviral and immunoregulatory activities $[11,12]$. It has also been shown that IFN- $\lambda$-mediated antiviral activity is linked to the activation of type I IFN-stimulated gene factor 3 (ISGF3) and the induction of IFN $\alpha / \beta$ - and IFN- $\lambda$-stimulated antiviral genes [13]. This provides a potential mechanism for the inhibitory effect of IFN- $\lambda$ on HSV-1. Additionally, IFN- $\lambda$ has the ability to activate the same JAK-STAT (Janus kinase-signal transducer and activator transcription factor) and MAP (mitogen-activated protein) kinase pathway as Type I IFNs [14-16].

Recent studies have reported a relationship between a specific polymorphism of IL28B (rs12979860) and HSV-1 reactivation in patients with herpes labialis [17], suggesting that polymorphisms in genes involved in antiviral responses might modulate the risk of developing recurrent HSV infection. Of note, this polymorphism was also reported to have a positive correlation with IFN- $\lambda 3$ serum levels and the treatment outcome in patients with hepatitis $C$ virus infection $[18,19]$. Treatment with IFN- $\lambda$ also inhibited virus replication and inflammatory reaction in an experimental model of HSK in mice [20].

The aim of this study was to evaluate possible correlations between host polymorphisms of the IL28B genotype and recurrent HSV keratitis in HSV-1 IgG-seropositive patients. To the best of our knowledge, the potential relationship between $I L 28 B$ genotype and recurrent HSK has not previously been previously reported.

\section{Materials and Methods}

\subsection{Study Setting}

This was an in vitro experimental study using material of human origin. The study was conducted in accordance with the Institutional Review Board regulations, adhered to the tenets of the Declaration of Helsinki, and informed consent was obtained from all participants.

The sample consisted of 80 patients over the age of 18 of both genders. All participants filled out a questionnaire to confirm their history of recurrent herpes simplex labialis (HSL) infection (cold sores). In addition, blood samples were collected from all patients in order to confirm the HSV1 IgG-positive status. Seventy-five of the tested patients were seropositive for HSV-1 and were subsequently enrolled in the study. 
Twenty-four of the enrolled patients also had a history of recurrent HSV keratitis, leading to severe corneal scarring and, consequently, visual acuity deterioration. Recurrences were classified as epithelial keratitis, stromal keratitis, endothelitis, iridocyclitis, or combinations of these conditions. All patients were followed up for at least one year, from January to December 2018, at the Clinic for Eye Diseases, Clinical Centre of Serbia, Belgrade. Participants with no history of herpetic eye disease were voluntary employees from the Scientific Institute of Veterinary Medicine of Serbia. Genotyping for IL28B (rs12979860snp) was performed in the laboratory of the Scientific Institute of Veterinary Medicine of Serbia.

\subsection{Inclusion and Exclusion Criteria}

The study included participants with a history of recurrent HSL infection and confirmed HSV-1 IgG-seropositive status. Participants lacking anti-HSV-1 IgG antibodies were excluded (5 out of 80). This selection step resulted in a main study sample of 75 subjects.

Inclusion criteria for patients exhibiting recurrent herpetic eye disease were as follows: recurrent herpetic keratitis associated with corneal scarring and neovascularization and significant deterioration of visual acuity (less than 6/60, Snellen).

Exclusion criteria were as follows: a history of associated ocular comorbidities and previous ocular surgery, systemic and neurological diseases.

\subsection{Immunological Analyses}

Five milliliters of peripheral venous blood was collected from each patient in order to identify HSV-1 IgG status. An enzyme immunoassay was conducted for the qualitative determination of IgG class antibodies against HSV Type 1+2 in human serum or plasma (GenWay Biotech, Inc., San Diego, CA, USA). The cut-off value was HSV1 IgG $<9$ NTU.

\subsection{Determination of IL28B Genotype}

Five milliliters of peripheral venous blood was collected from each patient in order to identify the polymorphic gene IL28B rs12979860.

Total DNA was isolated using a commercial QIAamp DNA Blood mini kit (QIAGEN, Hilden, Germany) in accordance with the manufacturer's instructions. The single-nucleotide polymorphism (SNP) rs12979860, near the IL28B gene on chromosome 19, was genotyped.

Polymorphism was evaluated using the Sequence-Specific Primer-Polymerase Chain Reaction (SSP-PCR) method, which multiplies a short DNA region upstream or downstream of the polymorphism with an allele-specific primer (Table 1) [21]. PCR products were analyzed in $2 \%$ agarose gel with ethidium bromide staining (Figure 1). Determination of individual-polymorphism genotypes was performed on the basis of the presence or absence of amplified target sequences. The amplification was performed using the following parameters: initial denaturation step at $95{ }^{\circ} \mathrm{C}$ for $5 \mathrm{~min}$, then 35 cycles at $95^{\circ} \mathrm{C}$ for $30 \mathrm{~s}, 58^{\circ} \mathrm{C}$ for $45 \mathrm{~s}, 72^{\circ} \mathrm{C}$ for $60 \mathrm{~s}$, and $72{ }^{\circ} \mathrm{C}$ for $10 \mathrm{~min}$.

Table 1. Nucleotide sequences of the primers used in this study. SNP: single-nucleotide polymorphism.

\begin{tabular}{ccc}
\hline IL28B SNP & Nucleotide Sequence & Size of PCR Product \\
\hline \multirow{3}{*}{ rs12979860 } & Gen (sense) 5' 5TATCGCATACGG CTAGGC-3' $^{\prime}$ & \\
& C (antisense) 5'TGCAATTCAACCCTGGTTC G-3' & 153 bp \\
& T (antisense) 5' TGCAATTCAACCCTGGTTC A-3 & \\
\hline
\end{tabular}




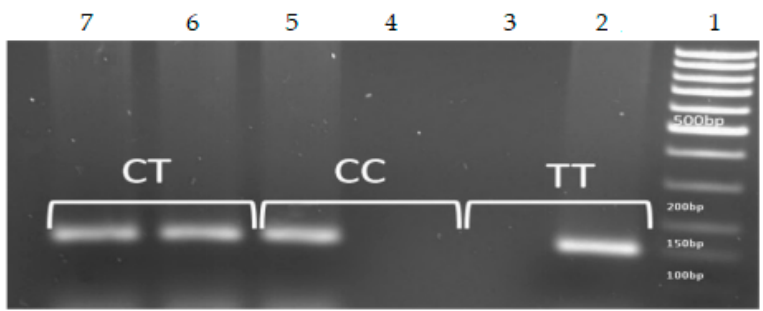

Figure 1. Polymorphism rs12979860-determination of genotypes (size of PCR product: $153 \mathrm{bp}$ ). Line 1, DNA ladder; lanes 2,3, TT homozygous; lanes 4,5, CC homozygous, Lines 6,7, CT heterozygous. Heterozygous samples resulted in the amplification of both bands, indicating the presence of the two alleles.

\subsection{Ethical Approval}

This study was approved by the Ethics Committee and the Institutional Review Board of Clinical Center of Serbia, Belgrade (decision No. 57/14, approved on 21 March 2019). Please mention that the study was done according to the Helsinki declaration.

\subsection{Statistical Analysis}

The statistical analysis was performed with SPSS Statistics 20. We used the Chi-square test to determine if there was an association between IL28b genotypes and prevalence of HSV infections.

The Chi-square independence test was applied in order to determine a possible association between IL28b genotypes and incidence of HSK infection; $p$-values below 0.01 were considered statistically significant. The calculation of the total sample was based on the results of other authors who had studied the impact of the examined genotype in subjects with labial herpes and patients with hepatitis C. Using a $G^{*}$ Power 3.1.9.4 and $\chi 2$ test with a significance level (alpha) of 0.01 and a study strength of 0.08 , it was deemed that a minimum number of 40 subjects was required to achieve significant results. The total sample size comprised 75 respondents; thus, the sample size was sufficient.

\section{Results}

\subsection{Clinical Characteristics}

This study included 75 participants with confirmed HSV IgG-positive status. Twenty-four patients had experienced recurrent HSK, and the remaining 51 individuals only had a history of recurrent HSL disease. The demographic characteristics of the study population are summarized in Table 2.

Table 2. Demographic characteristics of the study population.

\begin{tabular}{cc}
\hline Characteristics & All Patients \\
\hline $\mathrm{n}$ & 75 \\
Gender (M/F) & $36: 39$ \\
Age, y & $44.95 \pm 11.294$ \\
Have keratitis (M) & $5(6.7 \%)$ \\
Do not have keratitis (M) & $31(41.3 \%)$ \\
Have keratitis (F) & $19(25.3 \%)$ \\
Do not have keratitis (F) & $20(26.7 \%)$ \\
\hline
\end{tabular}

Data are reported as mean \pm standard deviation. $\mathrm{M}$, male; $\mathrm{F}$, female.

\subsection{Distribution of IL28B Genotype Polymorphisms}

The presence of the host IL28B rs1279860 genotype was investigated in all participants. The distribution of the polymorphism in the IL28B gene region for the study population as a whole is shown in Figure 2. CTrs1279860 was the most common genotype identified and was estimated to be present 
in $45 \%$ of patients (34 out of 75 ), followed by the CCrs 1279860 genotype, present in 35\%of patients (26 patients), and the TTrs1279860 genotype, observed in the remaining 20\% of patients (15 patients) (Figure 2).

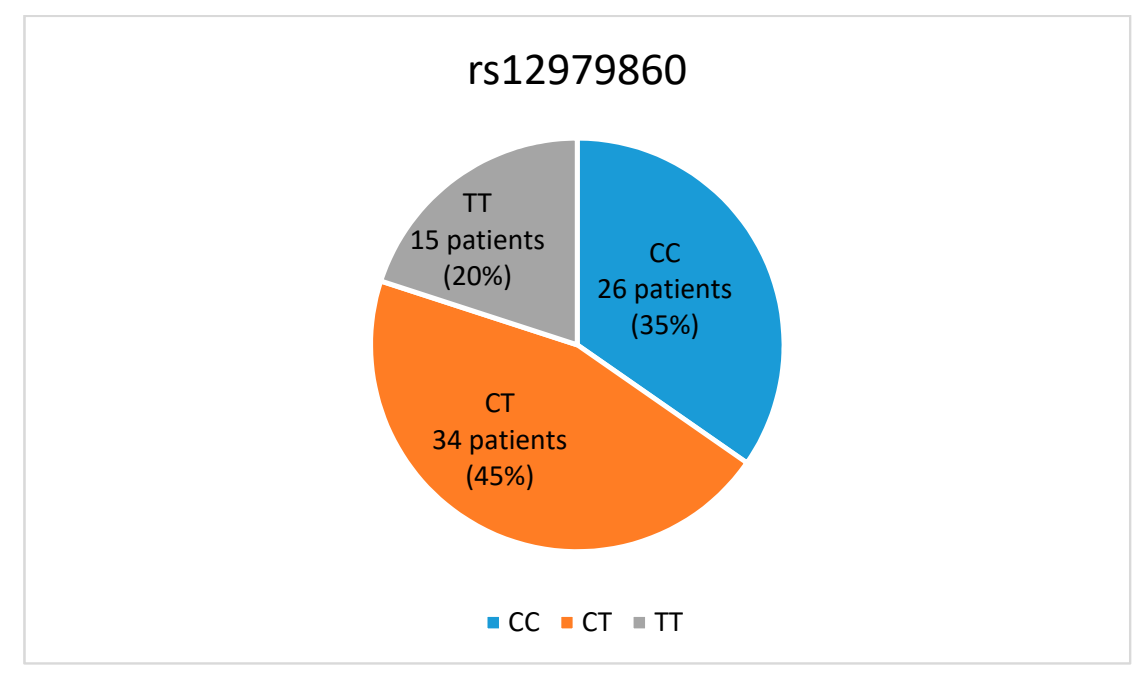

Figure 2. Distribution of the IL28B genotype rs12979860 in the study group as a whole. Percent distribution of the IL28B genotype rs12979860. CC: CCrs1279860, CT: CTrs1279860, TT: TTrs1279860.

A significant association was observed between recurrent HSV keratitis and two SNPs of the IL28B genotype (CCrs12979860 and CTrs12979860, $p<0.01$ ). Interestingly, the variation in CCrs12979860 showed a more significant association with recurrent HSV keratitis compared with CTrs12979860 (16 and 8 patients, respectively), as demonstrated in Figure 3. Furthermore, the TTrs12979860 genotype variant of IL28B was observed in 15 participants with HSV labialis disease. Of note, in our study, patients with recurrent HSV keratitis did not show the TTrs12979860 genotype variant (Figure 3).

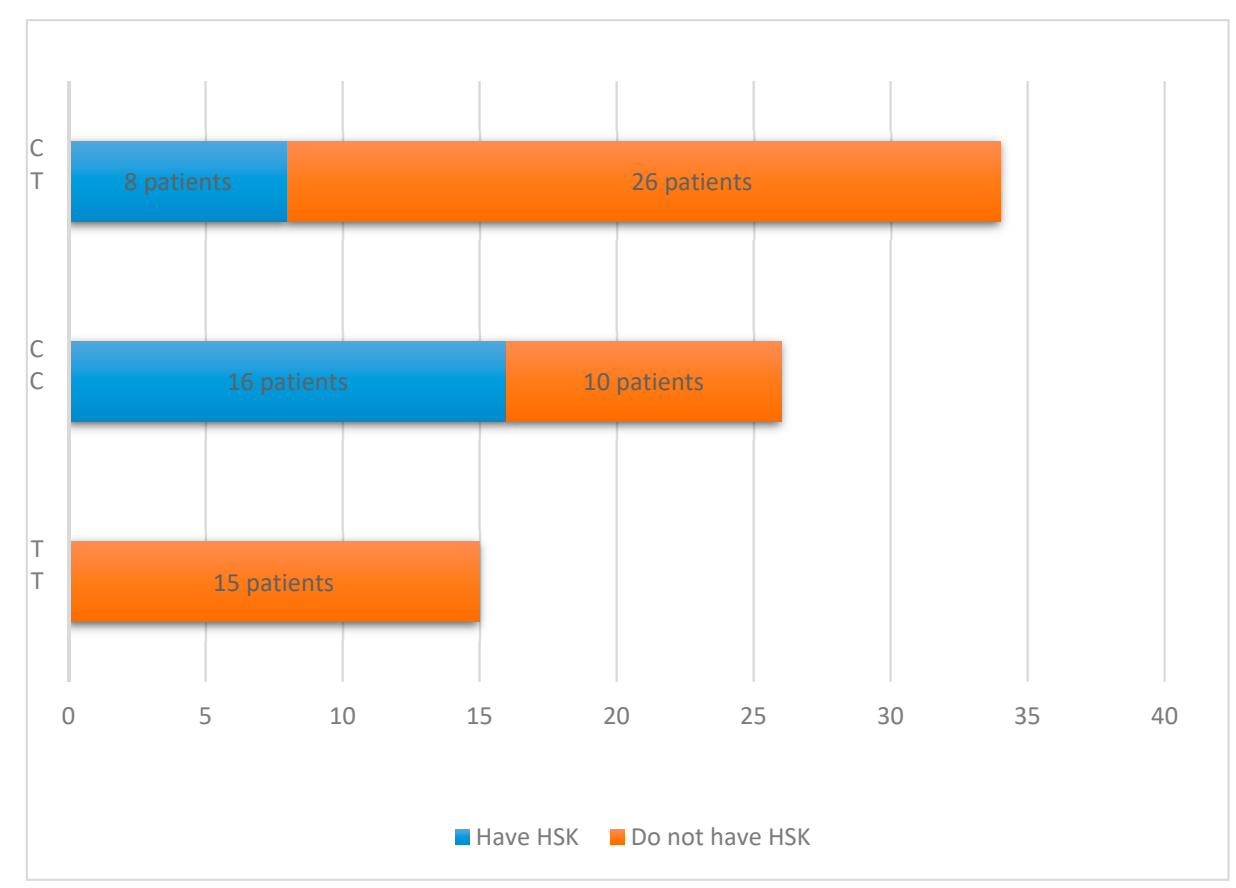

Figure 3. IL28B genotype distribution according to the clinical manifestation of recurrent herpes simplex virus (HSV) infection. Patients with herpes simplex keratitis (HSK) are marked in blue, and patients without HSK are marked in orange. 


\section{Discussion}

In our study, the polymorphism of the IL28B (rs12979860) gene was analyzed in HSV-1-seropositive patients with a history of recurrent HSV disease including HSV keratitis and/or herpes labialis. The CTrs12979860 genotype was the most common SNP variation in patients with recurrent HSV disease, followed by the CCrs12979860 and the TTrs12979860 genotypes. Interestingly, the majority of patients with recurrent HSV keratitis demonstrated the CC genotype (16 out of 24,66.7\%), whereas only 10 out of $51(19.6 \%)$ individuals with herpes labialis (without a history of recurrent HSV eye disease) showed the CC genotype variant of IL28B.

Recurrent stromal HSV keratitis is recognized as the most common infectious cause of vision-threatening corneal scarring in the developed world [22]. Accordingly, in our study, all patients with recurrent HSV keratitis exhibited severe corneal scarring accompanied by significant visual acuity reduction. The inflammatory process orchestrated by Th1 cells and non-lymphoid inflammatory cells leads to a chronic tissue-damaging response in addition to direct viral effects [4]. Most of the corneal damage results from neutrophil infiltration and neovascularization [23].

Studies with animal models have revealed that the genetic make-up of the host has an impact on the severity of HSV-1 corneal disease. Strains of inbred mice were shown to differ in their susceptibility to HSV corneal infection [24]. However, the roles of specific host genes in the resistance to HSK are poorly understood. Host genes may influence the outcome of an infection by affecting innate resistance factors as well as the function of the immune system [25]. It was also shown that susceptibility to HSV-1 infection is modulated by polymorphisms in genes that control the effector functions of cytotoxic $\mathrm{T}$ and natural killer (NK) lymphocytes [26].

A number of studies have investigated the relationship among host gene polymorphisms and both the severity and the recurrence of HSV infection $[17,26,27]$. In this context, it was recently reported that IFN- $\lambda$ gene expression is associated with the recurrence and severity of recurrent HSV-1 disease [17]. Indeed, the minor T allele at rs12979860 was found to be associated with the severity and frequency of labial herpes recurrence. Griffiths et al. found that individuals with the CT or TT genotypes for $I L 28 B$ had more frequent episodes of severe labial herpes, a condition resulting from the reactivation of HSV-1 [17]. On the basis of these findings, the authors suggested that recurrent HSV disease is likely to be associated with the IL28B polymorphism. Likewise, in our study, the CT and TT genotypes were more prevalent in individuals with isolated labial herpes. However, the CC genotype for IL28B was highly associated with recurrent HSK. It seems that both clinical manifestation and site of HSV reactivation from trigeminal ganglia might be related to different host genotypes as well as to the micro-environment. It is therefore of utmost clinical interest to identify a subgroup of patients with recurrent HSL who possess a higher risk for developing HSK, a potentially blinding disorder. Future studies with larger numbers of participants are necessary to confirm the hypothesis that the host genotype of IL28B might have an influence on determining which one of the three branches of trigeminal ganglion is most likely to be followed upon periodical HSV reactivation.

In patients with chronic hepatitis $C$, the CC genotype profile has been associated with a lower level of transcription of interferon-stimulated genes (ISGs) compared with TT individuals [28,29]. The non-CC genotypes, associated with a higher level of ISG expression in the setting of chronic hepatitis C infection, have previously been related to lower rates of spontaneous virus clearance. In contrast, the CC genotype, in which a low level ISG expression is observed, has been associated with high rates of spontaneous virus clearance [28].

The presence of the CC genotype variant in our patients with recurrent HSK might have led to incomplete control of infection and periodical viral shedding due to a lower transcription level of ISGs, as previously reported in patients with chronic hepatitis $C$ infection $[28,29]$.

Type III IFNs (IFN- $\lambda$ ) have been found to possess antiviral effects against HSV [30,31]. Pica et al. reported that reduced production of IFN- $\lambda$ might be correlated with the development of recurrent HSV-1 labialis in immunocompetent individuals [32]. A recent study reported that IFN- $\lambda$ treatment resulted in significant suppression of HSV-1 replication in both astrocytes and neurons. Furthermore, 
this was associated with the upregulation of endogenous IFN $-\alpha / \beta$ and several ISGs [13]. These findings indicate that IFN- $\lambda$ functionally resembles that of type I IFN, inducing ISG expression and resulting in the suppression of viral replication [13]. Immunological control of virus reactivation should also be taken into account. The environmental and physiologic stimuli that induce HSV-1 reactivation from latency include exposure to UV light, stress, and immune suppression, suggesting a possible role for T cells in preventing viral reactivation [33].

\section{Conclusions}

In our study, the CTrs12979860 genotype was found to be the most common SNP variation in patients with recurrent HSV disease, followed by CCrs12979860 and TTrs12979860.

While the CT and TT genotypes were more prevalent in individuals with isolated labial herpes, our results indicate that HSV-1-seropositive individuals expressing the CC IL28B genotype have a tendency toward developing recurrent herpetic keratitis. Clinical manifestation and the severity of recurrent HSV-1 infection seem to be influenced by polymorphism of the IL28B genotype. Further studies on host genetics in patients with recurrent herpetic eye disease are necessary to support our results.

Author Contributions: S.B. carried out the molecular genetic studies and drafted the manuscript, conceived the study, and participated in its design and coordination. S.S. participated in the design of the study and coordination and helped to draft the manuscript. Đ.N. participated in the design of the study and performed the statistical analysis. M.-Đ.O. participated in the design of the study and helped to draft the manuscript. H.-M.M. helped to draft the manuscript. M.F. helped to draft the manuscript. S.M. helped to draft the manuscript. P.S. helped to draft the manuscript. All authors have approved the final version of the manuscript.

Funding: This research received no external funding.

Conflicts of Interest: The authors declare no conflict of interest.

\section{References}

1. Boppana, S.B.; Fowler, K.B. Persistence in the population: Epidemiology and transmisson. In Human Herpesviruses: Biology, Therapy, and Immunoprophylaxis; Cambridge University Press: Cambridge, UK, 2007.

2. Smith, J.S.; Robinson, N.J. Age-specific prevalence of infection with herpes simplex virus types 2 and 1: A global review. J. Infect. Dis. 2002, 186, S3-S28. [CrossRef] [PubMed]

3. Liesegang, T.J. Herpes simplex virus epidemiology and ocular importance. Cornea 2001, 20, 1-13. [CrossRef]

4. Biswas, P.S.; Rouse, B.T. Early events in HSV keratitis-Setting the stage for a blinding disease. Microbes Infect. 2005, 7, 799-810. [CrossRef] [PubMed]

5. Miranda-Saksena, M.; Denes, C.E.; Diefenbach, R.J.; Cunningham, A.L. Infection and transport of herpes simplex virus type 1 in neurons: Role of the cytoskeleton. Viruses 2018, 10, 92. [CrossRef] [PubMed]

6. Shimeld, C.; Hill, T.; Blyth, B.; Easty, D. An improved model of recurrent herpetic eye disease in mice. Curr. Eye Res. 1989, 8, 1193-1205. [CrossRef] [PubMed]

7. Abdelfattah, N.S.; Amgad, M.; Zayed, A.A. Host immune cellular reactions in corneal neovascularization. Int. J. Ophthalmol. 2016, 9, 625-633. [PubMed]

8. Hochrein, H.; Schlatter, B.; O’Keeffe, M.; Wagner, C.; Schmitz, F.; Schiemann, M.; Bauer, S.; Suter, M.; Wagner, H. Herpes simplex virus type-1 induces IFN- $\alpha$ production via Toll-like receptor 9-dependent and-independent pathways. Proc. Natl. Acad. Sci. USA 2004, 101, 11416-11421. [CrossRef] [PubMed]

9. Leib, D.A. Counteraction of interferon-induced antiviral responses by herpes simplex viruses. In Viral Proteins Counteracting Host Defenses; Springer: Berlin/Heidelberg, Germany, 2002; pp. 171-185.

10. Kotenko, S.V.; Gallagher, G.; Baurin, V.V.; Lewis-Antes, A.; Shen, M.; Shah, N.K.; Langer, J.A.; Sheikh, F.; Dickensheets, H.; Donnelly, R.P. IFN- $\lambda$ s mediate antiviral protection through a distinct class II cytokine receptor complex. Nat. Immunol. 2003, 4, 69-77. [CrossRef]

11. Uzé, G.; Monneron, D. IL-28 and IL-29: Newcomers to the interferon family. Biochimie 2007, 89, 729-734. [CrossRef]

12. Srinivas, S.; Dai, J.; Eskdale, J.; Gallagher, G.E.; Megjugorac, N.J.; Gallagher, G. Interferon- $\lambda 1$ (interleukin-29) preferentially down-regulates interleukin-13 over other $\mathrm{T}$ helper type 2 cytokine responses in vitro. Immunology 2008, 125, 492-502. [CrossRef] 
13. Li, J.; Hu, S.; Zhou, L.; Ye, L.; Wang, X.; Ho, J.; Ho, W. Interferon lambda inhibits herpes simplex virus type I infection of human astrocytes and neurons. Glia 2011, 59, 58-67. [CrossRef] [PubMed]

14. Sheppard, P.; Kindsvogel, W.; Xu, W.; Henderson, K.; Schlutsmeyer, S.; Whitmore, T.E.; Kuestner, R.; Garrigues, U.; Birks, C.; Roraback, J.; et al. IL-28, IL-29 and their class II cytokine receptor IL-28R. Nat. Immunol. 2003, 4, 63-68. [CrossRef] [PubMed]

15. Dumoutier, L.; Tounsi, A.; Michiels, T.; Sommereyns, C.; Kotenko, S.V.; Renauld, J.C. Role of the Interleukin (IL)-28 Receptor Tyrosine Residues for Antiviral and Antiproliferative Activity of IL-29/Interferon- $\lambda 1$ similarities with type I interferon signaling. J. Biol. Chem. 2004, 279, 32269-32274. [CrossRef] [PubMed]

16. Zhou, Z.; Hamming, O.J.; Ank, N.; Paludan, S.R.; Nielsen, A.L.; Hartmann, R. Type III interferon (IFN) induces a type I IFN-like response in a restricted subset of cells through signaling pathways involving both the Jak-STAT pathway and the mitogen-activated protein kinases. J. Virol. 2007, 81, 7749-7758. [CrossRef] [PubMed]

17. Griffiths, S.J.; Koegl, M.; Boutell, C.; Zenner, H.L.; Crump, C.M.; Pica, F.; Gonzalez, O.; Friedel, C.C.; Barry, G.; Martin, K.; et al. A systematic analysis of host factors reveals a Med23-interferon- $\lambda$ regulatory axis against herpes simplex virus type 1 replication. PLoS Pathog. 2013, 9, e1003514. [CrossRef] [PubMed]

18. Ge, D.; Fellay, J.; Thompson, A.J.; Simon, J.S.; Shianna, K.V.; Urban, T.J.; Heinzen, E.L.; Qiu, P.; Bertelsen, A.H.; Muir, A.J.; et al. Genetic variation in IL28B predicts hepatitis C treatment-induced viral clearance. Nature 2009, 461, 399-401. [CrossRef] [PubMed]

19. Langhans, B.; Kupfer, B.; Braunschweiger, I.; Arndt, S.; Schulte, W.; Nischalke, H.D.; Nattermann, J.; Oldenburg, J.; Sauerbruch, T.; Spengler, U. Interferon-lambda serum levels in hepatitis C. J. Hepatol. 2011, 54, 859-865. [CrossRef]

20. Jaggi, U.; Bhela, S.; Rouse, B.T. Role of Interferon lambda (IL-28A) in Herpes Stromal Keratitis. J. Immunol. Res. Ther. 2018, 3, 135-144.

21. Hori, K.; Shin, W.S.; Hemmi, C.; Toyo-oka, T.; Makino, T. High fidelity SNP genotyping using sequence-specific primer elongation and fluorescence correlation spectroscopy. Curr. Pharm. Biotechnol. 2003, 4, 477-484. [CrossRef]

22. Rolinski, J.; Hus, I. Immunological aspects of acute and recurrent herpes simplex keratitis. J. Immunol. Res. 2014, 2014, 513560. [CrossRef]

23. Azher, T.N.; Yin, X.T.; Tajfirouz, D.; Huang, A.J.; Stuart, P.M. Herpes simplex keratitis: Challenges in diagnosis and clinical management. Clin. Ophthalmol. 2017, 11, 185-191. [CrossRef] [PubMed]

24. Metcalf, J.F.; Michaelis, B.A. Herpetic keratitis in inbred mice. Investig. Ophthalmol. Vis. Sci. 1984, 25, 1222-1225.

25. Brandt, C.R. The role of viral and host genes in corneal infection with herpes simplex virus type 1. Exp. Eye Res. 2005, 80, 607-621. [CrossRef]

26. Moraru, M.; Cisneros, E.; Gómez-Lozano, N.; de Pablo, R.; Portero, F.; Cañizares, M.; Vaquero, M.; Roustán, G.; Millán, I.; López-Botet, M.; et al. Host genetic factors in susceptibility to herpes simplex type 1 virus infection: Contribution of polymorphic genes at the interface of innate and adaptive immunity. J. Immunol. 2012, 188, 4412-4420. [CrossRef] [PubMed]

27. Russell, C.D.; Griffiths, S.J.; Haas, J. Interferon lambda genetic polymorphisms and viral infection: The tip of the iceberg? DNA Cell Biol. 2014, 33, 60-63. [CrossRef]

28. Abe, H.; Hayes, C.N.; Ochi, H.; Maekawa, T.; Tsuge, M.; Miki, D.; Mitsui, F.; Hiraga, N.; Imamura, M.; Takahashi, S.; et al. IL28 variation affects expression of interferon stimulated genes and peg-interferon and ribavirin therapy. J. Hepatol. 2011, 54, 1094-1101. [CrossRef] [PubMed]

29. Honda, M.; Sakai, A.; Yamashita, T.; Nakamoto, Y.; Mizukoshi, E.; Sakai, Y.; Yamashita, T.; Nakamura, M.; Shirasaki, T.; Horimoto, K.; et al. Hepatic ISG expression is associated with genetic variation in interleukin 28B and the outcome of IFN therapy for chronic hepatitis C. Gastroenterology 2010, 139, 499-509. [CrossRef] [PubMed]

30. Ank, N.; West, H.; Bartholdy, C.; Eriksson, K.; Thomsen, A.R.; Paludan, S.R. Lambda interferon (IFN- $\lambda$ ), a type III IFN, is induced by viruses and IFNs and displays potent antiviral activity against select virus infections in vivo. J. Virol. 2006, 80, 4501-4509. [CrossRef] 
31. Melchjorsen, J.; Sirén, J.; Julkunen, I.; Paludan, S.R.; Matikainen, S. Induction of cytokine expression by herpes simplex virus in human monocyte-derived macrophages and dendritic cells is dependent on virus replication and is counteracted by ICP27 targeting NF-kB and IRF-3. J. Gen. Virol. 2006, 87, 1099-1108. [CrossRef]

32. Pica, F.; Volpi, A.; Gaziano, R.; Garaci, E. Interferon- $\lambda$ in immunocompetent individuals with a history of recurrent herpes labialis. Antivir. Ther. 2010, 15, 737. [CrossRef]

33. Sainz, B.; Loutsch, J.M.; Marquart, M.E.; Hill, J.M. Stress-associated immunomodulation and herpes simplex virus infections. Med. Hypotheses 2001, 56, 348-356. [CrossRef] [PubMed]

C 2019 by the authors. Licensee MDPI, Basel, Switzerland. This article is an open access article distributed under the terms and conditions of the Creative Commons Attribution (CC BY) license (http://creativecommons.org/licenses/by/4.0/). 